\title{
Mourir debout
}

\section{Christina Aus der Au}

Prof., Dre en théol., membre de la rédaction Ethique

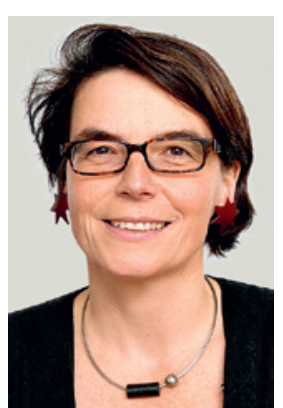

«Let me die in my footsteps, before I go down under the ground", chantait Bob Dylan dans son style poéticolaconique qui lui a valu le prix Nobel de littérature en 2016. Il y raconte comment les humains se laissent tellement terroriser par les rumeurs et théories du complot qu'ils en oublient de vivre. Ils apprennent à mourir plutôt qu'à vivre ("'Stead of learnin' to live they are learnin' to die»). Le chanteur, lui, veut mourir debout, pleinement vivant, plutôt que renoncer à la vie avant même qu'elle ne se termine.

Dylan a écrit cette chanson en 1962, en pleine guerre froide. Il a été témoin de la construction des abris antiatomiques et de la crise cubaine qui lui ont inspiré cette ode à la vie: boire de l'eau de source, humer le parfum des fleurs sauvages et s'en enivrer, dormir à la belle étoile, marcher pacifiquement dans la rue aux côtés de ses frères humains et mourir debout, avant de disparaître sous terre au fond d'un bunker.

Mourir debout, c'est aussi le souhait de Daniel, le médecin de famille atteint d'un cancer au stade terminal et protagoniste du roman Der letzte Zug (non traduit) de Ueli Greminger, ancien pasteur à l'église Saint-Pierre de Zurich. Dans ce récit, Daniel est l'interlocuteur agnostique et lucide de Peter, pasteur autocritique en désaccord avec l'Eglise [1]. Les deux protagonistes se lient d'amitié, discutent longuement du déclin de l'Eglise, du sens de la vie et de ce que devrait être une bonne mort. Ils parlent aussi de la médecine qui tient les hommes et les femmes sous sa coupe, comme le faisait jadis l'Eglise, à coup d'acharnement thérapeutique et de mesures visant à prolonger la vie. Des mesures que les médecins comme Daniel refuseraient si elles touchaient à leur propre vie.

Let me die in my footsteps est la chanson préférée de Daniel. Vivre pleinement jusqu'au bout et tirer sa révérence dignement. Pour y parvenir, il demande à son ami Peter de l'accompagner dans sa fin de vie et de l'assister dans son suicide sous le couvert d'une organisation d'aide au suicide. Mais le doute subsiste: Peter lui a-t-il seulement tendu le breuvage mortel ou le lui a-t-il fait prendre contre son gré comme le laisse entendre le témoignage de la femme de Daniel? Inculpé, l'ami pasteur est placé en détention provisoire, d'où il décrit ses états d'âmes au rythme de la chanson de Dylan. Qu'est-ce que la liberté? Pouvoir s'en aller tranquillement et dignement lorsqu'on estime que le temps est venu? Aider son ami par pitié et accepter de rompre avec ses devoirs professionnels? Peter est-il devenu à son insu un pion dans leur jeu? Mais dans le jeu de qui? De la médecine, pour qui l'assistance au suicide est mal délimitée? De l'Eglise qui, en évoquant la volonté de Dieu, élude la question par la prière? Ou Peter est-il devenu le jouet de Daniel qui le met au défi de sa dernière volonté?

Peter finit par démissionner et va chercher la paix et la liberté dans les vignes. En tant que vigneron, il découvre l'émerveillement - the master's hand in every leaf that trembles, in every grain of sand. Dans l'épilogue, Daniel lui apparaît une dernière fois inspirant à Peter le mot de la fin: la vérité ne se trouve pas dans la liberté qui est inatteignable, elle se trouve dans la nostalgie de celle-ci.

Des questions profondes des plus actuelles ces derniers temps. Comment vivre librement, dans la plénitude, et mourir? Qu'est-ce qui compte le plus, l'autodétermination ou l'aide au prochain? Dans quels domaines l'Eglise accompagne-t-elle les humains au plus profond d'eux-mêmes et dans quels cas pèse-t-elle comme un rocher sur la religion? Quand la médecine sert-elle à sauver des vies et quand empêche-t-elle de mourir dans la dignité? Et quand la peur nous faitelle nous terrer dans un bunker?

Le roman ne livre pas de réponses définitives, il se contente de poser des questions - concrètes et inscrites dans une histoire. Une histoire comme la vie en écrit rarement, mais où l'auteur cherche à élucider ce que l'on entend par droit à mourir dans la dignité. Il se bat contre les réponses toutes faites, qu'elles soient médicales ou ecclésiastiques. Le pasteur accompli et le médecin reconnu sont les pions de l'auteur: deux hommes blancs d'un certain âge, jouissant d'une bonne situation, qui se plaisent à réfléchir sous forme de métaphores musicales et littéraires et dont la famille ne joue qu'un rôle mineur. Leurs plaisirs se limitent à boire du vin et à se regarder le nombril. Un récit à lire avec un esprit critique afin d'y trouver ses propres questions et réponses, mais un récit digne d'être lu, assurément.

\section{Référence}

1 Greminger U. Der letzte Zug. Pfarrer Bodmer unter Verdacht. Zurich: TVZ; 2020 (non traduit). 